\title{
Factors Affecting Deforestation in Paunglaung Watershed, Myanmar using Remote Sensing and GIS
}

\author{
Myat Su Mon*1, Tsuyoshi Kajisa*2, Nobuya Mizoue*2 and Shigejiro Yoshida*2
}

\begin{abstract}
The objective of this study is to predict the factors affecting deforestation based on the relationship between detected forest cover changes and biophysical factors of the study area by using spatial and statistical analysis. The study area is Paunglaung watershed, one of the important watersheds in Myanmar. This study used maximum likelihood classification (MLC) to compare Landsat TM images of 1989 and Landsat ETM + images of 2000 in order to assess deforestation. The study revealed that $32.61 \mathrm{~km}^{2}$ or $0.7 \%$ of the forest cover was annually lost in the watershed area. An empirical spatial model of deforestation was developed by relating a set of variables measuring landscape attributes to the spatial occurrence of deforestation. Variables derived from the GIS based analysis were used to verify spatially the close statistical relationship between dependent and independent variables by logistic regression model. This study provides both statistical and spatial confirmation of the importance of access in the location of deforestation.
\end{abstract}

Keywords: Landsat images, maximum likelihood classification (MLC), GIS, logistic regression, deforestation.

\section{INTRODUCTION}

Deforestation and forest degradation in developing countries have been major environmental concerns over the past few decades. As forest cover changes are particularly severe in the tropics and have significant global impacts (NAGENDRA et al., 2003; SOUTHWORTH et al., 2004), the destruction of tropical forests has received worldwide attention due to the significant effect on climate, carbon sequestration, water cycle and biodiversity (FEARNSIDE, 1997; TUCKER et al., 2005). On the other hands, the forests of Southeast Asia comprise some of the world's most valuable and productive tropical forests, forming unique ecosystems of high biodiversity composition (STIBIG et al., 2007). Deforestation and forest fragmentation are leading to the major threats to the flora and fauna that live therein (ZHAO et al., 2006). Tropical deforestation and forest degradation has been occurring at an unprecedented rate and scale in Southeast Asia (GIRI et al., 2003) and forest loss has remained at high levels during the period from the year 2000 to 2005 (FAO, 2005). The actual rate of deforestation varies over time and from region to region and is difficult to determine (BAWA and DAYANANDAN, 1997; GUPTA et al., 2004).

Repeated observations of satellite images and/or aerial photographs are useful for both visual assessment of natural resources dynamics occurring at a particular time and space as well as quantitative evaluation of land cover changes (TEKLE and HEDLund, 2000). Analysis and presentation of such data can be greatly facilitated through the use of GIS (ESCAP, 1997). Therefore, a combined use of remote sensing (RS) and GIS technologies can be invaluable to address a wide variety of resource management problems including the assessment of land cover changes and its causes (GAUTAM et al., 2003). Time series analysis of land cover change and the identification of the driving forces responsible for these changes are needed
Corresponding author: Myat Su Mon

${ }^{* 1}$ Laboratory of Forest Management, Department of Forest and Forest Products Sciences, Graduate School of Bioresource and Bioenvironmental Sciences, Kyushu University

\footnotetext{
${ }^{* 2}$ Faculty of Agriculture, Kyushu University 812-8581, Laboratory of Forest Management, Kyushu University, 6-10-1 Hakozaki, Higashi-ku, Fukuoka, Japan Tel: +81-92-642-2868

E-mail: myatsumon@bpes.kyushu-u.ac.jp
} 
for the sustainable management of natural resources and also for projecting future land cover trajectories (GIRI et al., 2003).

Myanmar is endowed with a highest percentage of forest cover in the Asia Pacific region; forests cover is $49 \%$ of the total land area of $676,000 \mathrm{~km}^{2}$ (STIBIG et al., 2007). The overall deforested area between 1955 and 1997 was about $3,160 \mathrm{~km}^{2}$ per year indicating that the actual forest area was annually decreasing at a rate of $0.5 \%$ of the total land area of the country (Forest Department, 2003; Than, 2000). However, FAO estimated that Myanmar is losing forest cover at a rate of $1.3 \%$ per year for $1990-2000$ and $1.4 \%$ per year for $2000-2005$ periods (FAO, 2005).

The study area, Paunglaung watershed, Myanmar is an important sub-catchment for Paunglaung multi-purpose dam which is intended to produce electricity and water irrigation. Therefore, conservation of forest cover in the upland watershed areas is crucial to get adequate water supply for the dam. Rural communities living in the watershed traditionally depend upon the natural resources, mainly forest resources for their livelihood. Due to increased population and continuous expansion of shifting cultivation, adverse effects and consequences in terms of deforestation, soil erosion, loss of biodiversity and watershed degradation are mounting in the study area (MYINT et al., 2002). Measures contributing to the emergence of a proper watershed management should urgently be taken based on the dynamic of forest cover changes. However, there was no systematic regional scale land cover change assessment and deforestation study for the Paunglaung watershed area. With this respect, detection on the land cover changes in Paunglaung watershed was conducted during the period of 1989 and 2000.

Factors affecting deforestation and land cover changes have been attributed by various reasons and those reasons are site specific (GIRI et al., 2003). Various spatial, statistical analysis of deforestation has already been applied in other countries, and these researches were attempted to identify predictors of the location of areas with the greatest propensity for deforestation (MERTENS et al., 1997). However, the information related with deforestation and land cover change model is very limited in Myanmar. The present study was conducted in order to fulfill the objectives; 1) to detect the changes of land covers of the study area between 1989 and 2000 through the application of RS and GIS; and 2) to predict the possibility of driving factors of deforestation through the establishment of a spatial logistic regression model.

We used logistic regression model to predict the driving factors of deforestation. The available biophysical data and location of the human settlement were applied to understand the potential driving factors of deforestation. The development of models of deforestation processes is motivated by several potential benefits to provide a better understanding of the causes and mechanisms governing deforestation, to generate predictions of future rates of deforestation and locate future forest clearing and, to support the design of policy responses to deforestation (LAMBIN, 1994; MAS et al. 2000).

\section{METHODOLOGY}

Study Sites

The study area, Paunglaung watershed is located in central Myanmar and lies between latitudes $19^{\circ} 20^{\prime}$ to $20^{\circ} 35^{\prime}$ north and longitudes $96^{\circ} 15^{\prime}$ to $97^{\circ} 00^{\prime}$ east (Fig. 1). It covers an area of about $4,600 \mathrm{~km}^{2}$ and most areas are mountainous with altitudes ranging from $180 \mathrm{~m}$ to $1,800 \mathrm{~m}$ above sea level. The study area is falling mainly in two administrative boundaries, Manadalay Division and Shan State. Generally, precipitation of the study area is higher in the eastern parts, i.e. Shan State and maximum and minimum annual total rainfalls are $2,167 \mathrm{~mm}$ and $812 \mathrm{~mm}$, respectively (Local Meteorological and Hydrological Stations). Drainage is predominantly north to south and Paunglaung river is the main stream which running from north to south and turns to the west in the middle of the study area. Forests cover most parts of the watershed and they can be broadly classified as mixed deciduous forests and evergreen forests (FOREST DEPARTMENT, 1998a and 1998b). Mixed deciduous forests, which are by far one of the commercially important forests in the country, are found mostly in the parts of lower elevation area whereas areas at high elevations are covered with an evergreen type of forests. This area is an important source for both local and commercial timber supply. Besides, this watershed is also an important habitat for wild fauna including tiger, elephant and various wildlife species (WILDLfFE CONSERvation Society, 1997). This area is also crucial to supply efficient water to Paunglaung dam that was located on the Paunglaung river (Fig. 1). It is first and largest underground facility project in Myanmar to supply electricity amounting to about 900 million kilowatt/hour annually and to irrigate water for 28,330 ha of various crops (IRRIGATION DePARTMEnT, 2004). Accordingly Paunglaung watershed has diverse intrinsic values not only for the local and national economy but also for biological diversity conservation (ZIN, 2005).

\section{Land Cover Change Assessment between 1989 and 2000}

The main data used in land cover change assessment included landsat images, Landsat 5/TM for 1989 and Landsat $7 / \mathrm{ETM}+$ for 2000 (Table 1 ). The study area was related to the area common to three landsat images, i.e. 133-46, 132-46 and 132-47 (Fig. 1.c).

Landsat TM satellite images of 1989 which were already georeferenced to the coordinate system of the study area (WGS84, projection: UTM, zone $46 \mathrm{~N}$ ) were used as master images for georeferencing and image to image co-registration for the images of 2000. Classifications procedures were applied for TM images of two years using TNTmips 6.9 (Fig. 2). Band 


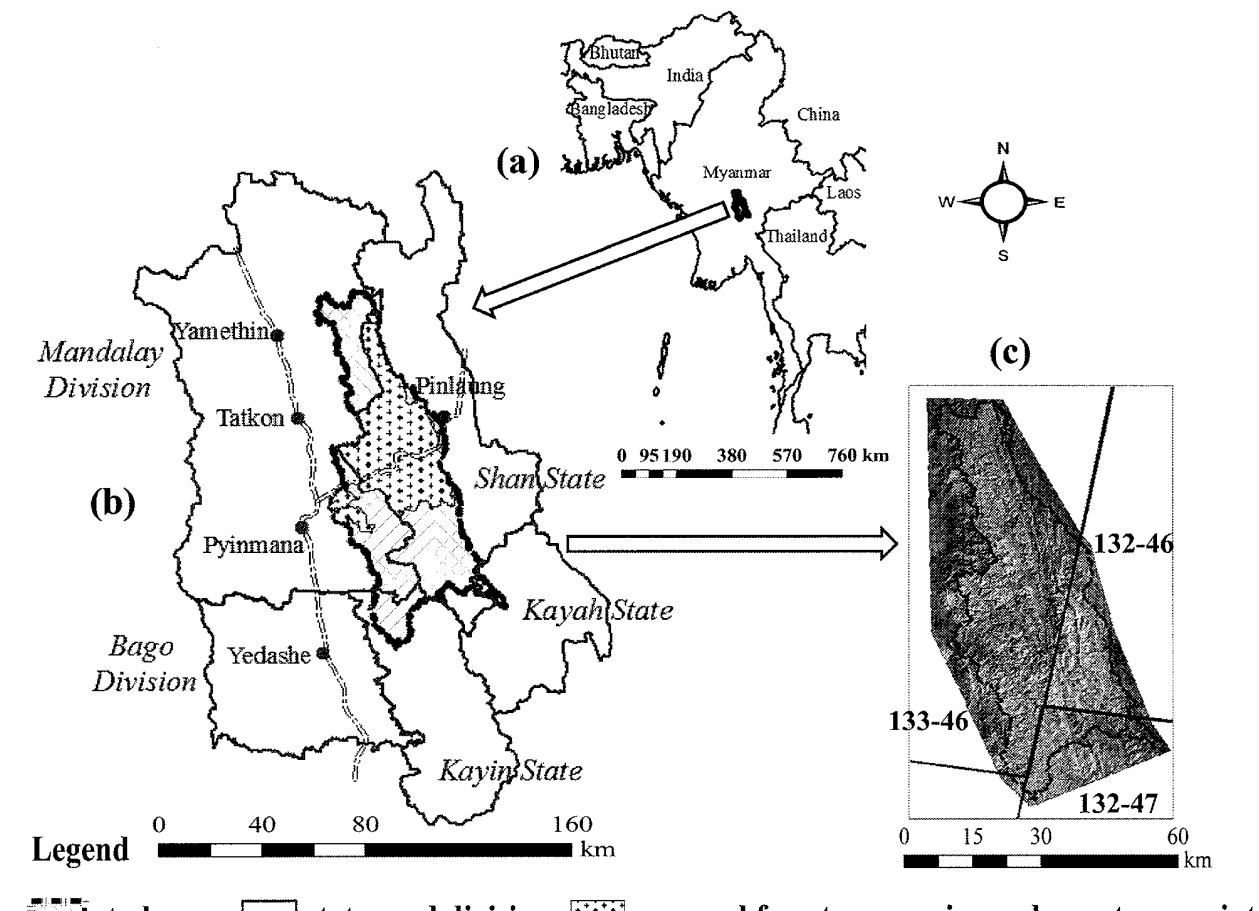

Fig. 1 Location of study area, Paunglaung watershed. (a) Study area located in central Myanmar. (b) Study area and its surrounding regions. (c) Paths and rows of three Landsat images used in the study

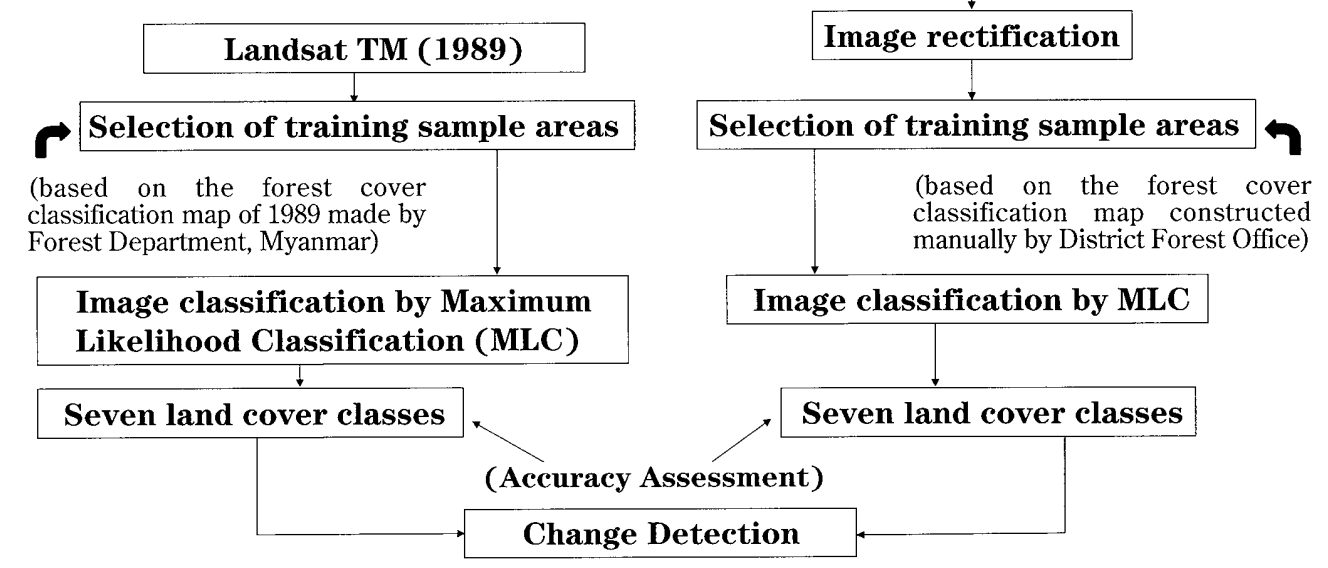

Fig. 2 Land cover change assessment between 1989 and 2000

Table 1 Images used for assessment of land cover changes of Paunglaung watershed

\begin{tabular}{ccccc}
\hline No. & Year & Scenes (Path \& Row) & Satellites & Acquisition Date \\
\hline \multirow{3}{*}{1.} & \multirow{2}{*}{1989} & $132 \_46$ & Landsat 5/ TM & $10-2-1989$ \\
& & $132 \_47$ & & $10-2-1989$ \\
& & $133 \_46$ & & $16-1-1989$ \\
\hline \multirow{2}{*}{2.} & \multirow{2}{*}{2000} & $132 \_46$ & Landsat 7/ ETM + & $24-1-2000$ \\
& & $132 \_47$ & & $23-12-1999$ \\
& & $133 \_46$ & & $4-4-2000$ \\
\hline
\end{tabular}


combination of band 4 (Red), band 5 (Green), and band 3 (Blue) of Landsat5/TM and Landsat7/ETM + satellite scenes was used in visual image classification. This is the best band combination used effectively for vegetation cover classification (SIDJAK and WHEATE, 1999).

Ancillary data such as ground verification records and vegetation maps were considered during the selection of training areas in order to obtain the greatest accuracy of the classification results (HUTCHINSON, 1982). Training areas representing the homogeneous spectral characteristics of the defined land cover categories, i.e., 10 to 13 of land cover categories related to the study area were selected to perform supervised classification. More than twenty training samples for each category were created visually by Area of Interest (AOIs) based on the homogeneity of the reflectance pixel values. For 1989, training samples were selected based upon the forest cover classification map conducted by Forest Department, Myanmar under the UNDP/FAO National Forest Management and Inventory Project in 1989. For 2000, training samples were selected based on the forest cover map prepared manually by the district forest office.

Maximum Likelihood Classification (MLC) was conducted by using the selected training samples in the analysis of multi-spectral image data. Classified land cover classes were finally combined into seven land cover classes; namely forest land, degraded forest land, waterbody, scrub and grass land, shifting cultivation, cultivated land and bare land including built-up areas (Table 2). For accuracy assessment, it was impossible to get the GPS positions of actual ground data for 1989 and 2000. Ground data, totally 140 GPS points (twenty GPS points for each land cover class) were obtained by the knowledge based data accepted from the interview survey with the local communities in the late 2004 and in the early 2005. After checking the accuracy of the classified images by classification error matrix, two land cover thematic maps were exported and overlaid in ArcGIS 9.1 to detect the forest cover changes of the study area. Actual change can be obtained by a direct comparison between classification results of one date with the other date. Temporal condition of land covers that have occurred between the two dates were measured by performing a change matrix (HOWARTH and WICKWARE, 1981).

\section{Establishment of Logistic Regression Model}

Logistic regression is a technique for analyzing problems in which there are one or more independent variables that determine an outcome and the outcome is measured with a dichotomous variable (in which there are only two possible outcomes) (MENARD, 1995; PAMPEL, 2000). Logistic regression model was constructed based upon the spatial information of forest cover changes as dependent variable and eight biophysical factors as independent variable explanatory to predict the possibility of deforestation.

\section{Generation of Dependent Variables}

The spatial prediction of deforestation or land cover changes requires an understanding of the proximate causes of changes (SERnEels and LAMBIN, 2001). Deforestation taken place over eleven year period was detected as dependent variables based on the change detection. The addressed question to detect dependent variables was "where deforestation is taking place?" Land cover classification maps of 1989 and 2000 were simplified by seven land cover classes. Then forest and degraded forest were grouped into forest and other five classes into non-forest. The final images after completing this processing were binary coded using pixel size of $30 \times$ $30 \mathrm{~m}$. Images were then overlaid in order to produce a digital map of deforestation that presents changes or decrease of forest cover. Some change combinations such as non-forest/ non-forest or non-forest/forest (increase) were neglected in this analysis because this study focuses on the modelling of deforestation process only. As the interest is to determine the predictors for deforestation, the numerical coding for deforestation was 1 for yes (decreased of forest cover) and 0 for no (no change forest cover). Therefore, the deforestation thematic map present only two classes, deforestation taking place, coded as 1 and no-deforestation taking place, coded as 0 between 1989 and 2000 .

\section{Generation of Independent Variables}

Independent variables used in logistic regression model were conducted and extracted from various GIS layers related with biophysical factors, accessibility and villages' locations of

Table 2 Recoding land cover classes in the study area

\begin{tabular}{ll}
\hline Land cover class & Characteristics \\
\hline forest land & forest with more than $40 \%$ canopy cover \\
degraded forest land & forest with $10-40 \%$ canopy cover \\
shifting cultivation & area currently under shifting cultivation, fallow land \\
cultivated land & permanent agriculture land, home garden \\
scrub and grass land & forest with less than $10 \%$ canopy cover \\
bare land & villages, roads, non-vegetative areas \\
waterbody & river, streams \\
\hline
\end{tabular}


the study area. The road network, stream network, town points and village points were manually digitized from topographic maps of 1: 63,360 scale, published in 1945 by the Survey Department of Myanmar and updated with 2000 Landsat satellite images and local administrative records. A digital elevation model (DEM) was constructed in TNTmips based on the contour lines; at an interval of $50 \mathrm{ft}(15.24 \mathrm{~m})$ that were also digitized from topographic maps. The thematic soil map of the study area was extracted from the Myanmar soil distribution map based on the FAO soil classification system and prepared by Land use division of Myanmar Agriculture service.

\section{Generation of GIS Layers}

i) Distance to roads: We used the road network which consists of two main roads (Fig. 1(b)) in this analysis as other roads can be used only during summer and especially used for timber extraction purpose. This variable was calculated as a series of buffers of $1 \mathrm{~km}$ expanding from the road network.

ii) Distance to towns: Five towns where there are large markets, government services, and hospitals etc; located around the study area were taken into account to detect the variable in the model. Distances were calculated as a series of $1 \mathrm{~km}$ buffer, expanding from the town points.

iii) Distance to villages: Totally 88 villages located in the study area were registered based on the topographic map and official records. Local communities are practicing shifting cultivation for subsistence living by clearing nearby forests around their villages. The areas around human settlements are mostly under the shifting cultivation cycle. They also established permanent agriculture like horticultural farms and low land rice cultivation for commercialization process (ZIN et al., 2002). We hypothesized that there may be some effects on forest cover surrounding the village. A series of buffer circle of $1 \mathrm{~km}$ radius from the village point was created for all the villages.

iv) Distance to water resources: Distance to water resources was calculated as a series of buffer of $1 \mathrm{~km}$, expanding from each stream network of the river and streams.
Accessibility to permanent water sources is highly valued because most of the local community need regular access to water resources for daily use, livestock and agriculture.

v) Area under logging: According to the logging records of Myanmar Timber Enterprise, logging activities were conducted within the three reserved forests of the study area and not within the other regions (Fig. 1(b)) during the period of 1990s. Logging creates access roads that might encourage surrounding communities into forests for agricultural expansions especially shifting cultivation and illegal logging, thus a higher possibility of future deforestation was expected due to the logging concessions. Unfortunately, we could not define specific areas of logging within the reserved forest for concessions, and we used three reserved forests boundary and separated study areas into two, reserved forest as logging area and outside reserved forest as non logging area. Polygon features were coded as 1 for reserved forest and as 0 for others.

vi) Soil types: The exploratory soil map for the study area was extracted from the soil type distribution map of Myanmar made by Land use division of Myanmar Agriculture service under FAO project. The suitability for agriculture depends on the soil type. The possibility of clearing of forest for agricultural purpose is leading to deforestation. In the study area, there are four soil types, i.e. meadow and meadow alluvial soil (Gleysol Fluvic), red earths and yellow earths (Acrisols), light forest soil (Nitosol), and mountainous brown forest soil (Cambisol). Those soil types were coded according to the level of agricultural suitability indicating from smaller coded to higher coded categories. We coded meadow and meadow alluvial soil as 1 , red earths and yellow earths as 2, light forest soils as 3 and mountainous brown forest soil as 4 .

vii) Elevation and slopes: DEM created by surface modelling of TNTmips was exported into ArcGIS by $30 \times 30 \mathrm{~m}$ raster layer. Slope layer was created based on DEM by spatial analysis of ArcGIS.

The above eight GIS layers were created with coded attributes according to their categories, $0,1,2$ and 3 , etc. (Table 3) and all layers were converted and used as raster data

Table 3 GIS database used in logistic regression model

\begin{tabular}{llll}
\hline Variables & Type & Unit & How to generate \\
\hline Deforestation & Binary & $\mathbf{0 - 1}$ & Change detection (1989-2000) \\
Distance to roads & Continuous & $\mathrm{km}$ & From road network \\
Distance to towns & Continuous & $\mathrm{km}$ & From town points \\
Distance to villages & Continuous & $\mathrm{km}$ & From village points \\
Distance to water resources & Continuous & $\mathrm{km}$ & From stream network \\
Soil types & Categorical & $1-4$ & Extracted from soil type distribution map of Myanmar \\
Area under logging & Binary & $0-1$ & Timber logging records \\
Elevation & Continuous & meter & From contour map/DEM \\
Slope & Continuous & degree & DEM \\
\hline
\end{tabular}

\section{J. For. Plann. 14:7-16(2009)}


source by using pixel size of $30 \times 30 \mathrm{~m}$. SPSS logistic regression models the relationship by computing the changes in the likelihood of falling in the categories of the dependent variable which has the highest numerical (CHAN, 2004; SCHWAB, 2004).

\section{Sampling Procedure}

Prior to performing the logistic regression, random points were created to select $\mathrm{N}$ observation points by the spatial extensions of Hawths tool of ArcGIS and the minimum distance between points is $1 \mathrm{~km}$. A random sample of 3,201 observations was selected and that distributed throughout the study area. Their attributes for dependent variables and independent variables were extracted by GIS and then logistic regression model was constructed by SPSS 11.5 .

\section{Logistic Regression Model}

We modelled the logistic regression by SPSS to test the relationship between a dichotomous dependent variable (occurance of deforestation/ no occurance of deforestation) and eight independent variables of biophysical and location data. The overall ability of the independent variables to predict the dependent variable was compared.

Before establishing the logistic regression model, multicollineariy test was conducted by linear regression and checking variance inflation factor (VIF) and tolerance because this is necessary to avoid collinearity between the independent variables (GARSON, 1998). When VIF is high, there is high multicollinearity and for tolerance $>0.20$ or VIF $<4$ suggest no multicollinearity (Belsley et al., 1980). The test showed no collinearity with the tolerance ranging from 0.27 to 0.99 which is higher than the critical value of 0.20 and all VIF were less than 4 (Table 4). Therefore, all the independent variables were used in the establishment of logistic regression by binary logistic regression analysis.

The fitting of the logistic regression model was assessed using model chi-square statistics $(p<0.05)$, which is an overall measure under the null hypothesis of perfect fit, and indicates the relationship between dependent variable and independent variables.

\section{RESULTS}

\section{Assessment of Land Cover Changes}

The overall accuracy of land cover classification for 1989 is $87.1 \%$ (Kappa Statistics of 0.86 ) whereas for 2000 the accuracy is $84.3 \%$ (Kappa Statistics of 0.82 ).

Total forest area decreased from $2,837 \mathrm{~km}^{2}$ to $2,478 \mathrm{~km}^{2}$

Table 4 Multicollinearity test for the independent variables

\begin{tabular}{|c|c|c|c|c|c|c|c|}
\hline & Unstandardized coefficients & ients Stan & Standardized coefficients & \multirow[t]{2}{*}{$\mathrm{t}$} & \multirow[t]{2}{*}{ Sig. } & \multicolumn{2}{|c|}{ Collinearity statistics } \\
\hline & $\mathrm{B}$ & Std. Error & Beta & & & Tolerance & VIF \\
\hline (Constant) & 0.492 & 0.040 & & 12.317 & 0.000 & & \\
\hline slope & 0.005 & 0.010 & 0.008 & 0.476 & 0.634 & 0.995 & 1.006 \\
\hline elevation & -0.051 & 0.010 & -0.125 & -5.294 & 0.000 & 0.540 & 1.851 \\
\hline soiltypes & -0.068 & 0.012 & -0.125 & -5.917 & 0.000 & 0.673 & 1.486 \\
\hline logging/non & 0.183 & 0.018 & 0.245 & 10.257 & 0.000 & 0.523 & 1.910 \\
\hline dis-road & 0.005 & 0.001 & 0.197 & 5.982 & 0.000 & 0.276 & 3.318 \\
\hline dis-town & -0.003 & 0.001 & -0.114 & -3.572 & 0.000 & 0.295 & 3.289 \\
\hline dis-water & -0.007 & 0.002 & -0.110 & -4.937 & 0.000 & 0.602 & 1.662 \\
\hline dis-village & 0.005 & 0.000 & 0.002 & 0.137 & 0.891 & 0.997 & 1.003 \\
\hline
\end{tabular}

notes: logging/non: area under logging or not, dis-road: distance to roads, dis-town: distance to towns, dis-water: distance to water resources, dis-villages: distance to villages.

Table 5 Change matrix for land cover classes $\left(\mathrm{km}^{2}\right)$ of 1989 and 2000

\begin{tabular}{lcccccccc}
\hline & For & Deg-For & SC & Culti-land & Sc-Gr & Bare Land & WB & 1989 \\
\hline For & $\mathbf{1 , 8 5 7 . 1}$ & 210.4 & 388.0 & 60.7 & 318.2 & 2.8 & 0.0 & 2837.2 \\
Deg-for & 598.7 & $\mathbf{2 6 2 . 4}$ & 41.0 & 40.7 & 52.2 & 1.8 & 0.1 & 997.0 \\
SC & 10.6 & 42.3 & $\mathbf{1 6 3 . 5}$ & 78.1 & 127.8 & 5.2 & 0.0 & 427.5 \\
Culti-land & 12.0 & 16.9 & 23.7 & $\mathbf{3 8 . 7}$ & 72.9 & 5.2 & 1.3 & 170.6 \\
Sc-Gr & 0.0 & 0.0 & 9.4 & 31.2 & $\mathbf{6 5 . 7}$ & 3.6 & 1.3 & 111.2 \\
Bar & 0.0 & 0.0 & 4.9 & 29.8 & 31.0 & $\mathbf{1 1 . 4}$ & 0.0 & 77.1 \\
WB & 0.0 & 0.0 & 0.0 & 9.1 & 0.0 & 0.7 & $\mathbf{1 . 4}$ & 11.3 \\
\hline 2000 & 2478.4 & 532.0 & 630.5 & 288.3 & 667.9 & 30.7 & 4.1 & $\mathbf{4 , 6 3 1 . 9}$ \\
\hline
\end{tabular}

notes: For $=$ forest land, Deg-For $=$ degraded forest land, $\mathrm{SC}=$ shifting cultivation, Culti-land $=$ cultivated land, $\mathrm{Sc}-\mathrm{Gr}=\mathrm{scrub}$ and grass land, Bare $=$ bare land and $\mathrm{WB}=$ waterbody 
(Table 5) although degraded forest land and other land covers positively converted to forest area, i.e. $621 \mathrm{~km}^{2}$. Forests were converted into degraded forests mostly in the western part of Paunglaung watershed (Fig. 3). Forest area of $210 \mathrm{~km}^{2}$ negatively changed to degraded forest land. However, total degraded forest area was decreased from $997 \mathrm{~km}^{2}$ to $532 \mathrm{~km}^{2}$ because $735 \mathrm{~km}^{2}$ degraded forest land changed into other land cover, i.e. shifting cultivation, cultivated land, scrub-grass land and bare land.

Total area of shifting cultivation increased up to $631 \mathrm{~km}^{2}$ in 2000 from $428 \mathrm{~km}^{2}$ in 1989 . Short fallow period for shifting cultivation was observed in the study area (ZIN et al., 2002; MYINT et al., 2002), This consequently lead to the increase of scrub and grass land from $111 \mathrm{~km}^{2}$ in 1989 to $668 \mathrm{~km}^{2}$ in 2000 .

Some forest areas around villages and stream banks changed into cultivated lands. That was frequently observed along the bank sites of the Paunglaung river (Fig. 3). Total area of cultivated land increased up to $288 \mathrm{~km}^{2}$ in 2000 from $171 \mathrm{~km}^{2}$ in 1989 (Table 5), and conversion was mostly observed in the eastern parts of the watershed.

Total bare land areas also decreased between 1989 and 2000 from $77 \mathrm{~km}^{2}$ to $31 \mathrm{~km}^{2}$. This changes mostly related with conversion into shifting cultivation, cultivated land and scrub and grass land; i.e. $4.9 \mathrm{~km}^{2}$ of bare land areas converted to shifting cultivation, $29.8 \mathrm{~km}^{2}$ to cultivated land and $31 \mathrm{~km}^{2}$ to scrub and grass land respectively (Table 5).

The comparison of the areas of seven land cover classes of the study area between 1989 and 2000 is expressed in Fig. 4. The results of the classification of land covers show that forest area decreased by $7.7 \%$ from 1989 to 2000 . The area under degraded forest also declined 10.0\% between 1989 and 2000 . On the other hands, scrub and grass land, shifting cultivation and cultivated land increased $12.0 \%, 4.4 \%$ and $2.5 \%$ of the total area respectively during the two periods.

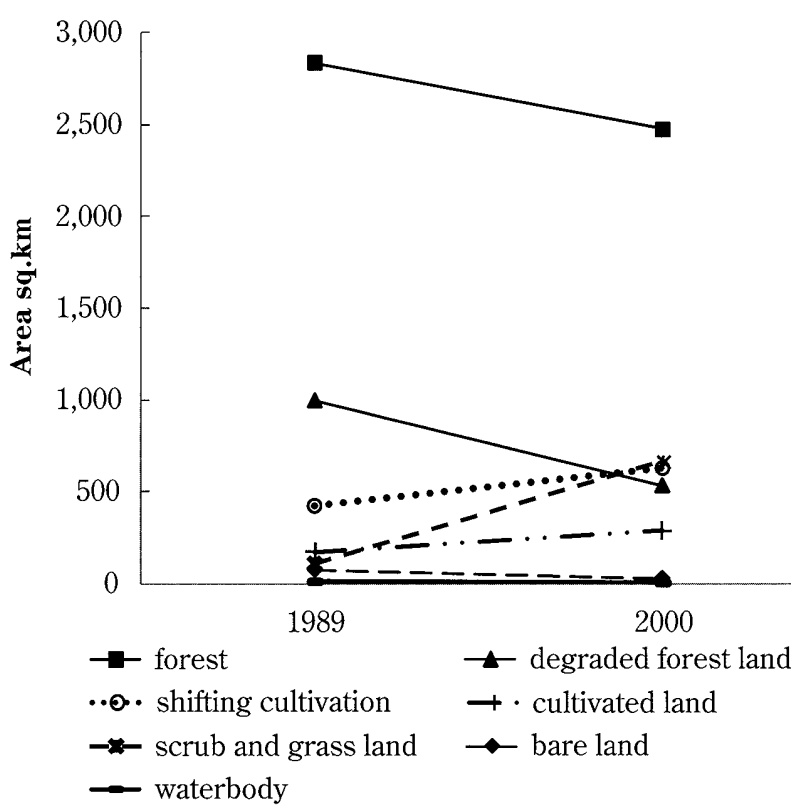

Fig. 4 Comparisons of areas of land cover classes for 1989 and 2000
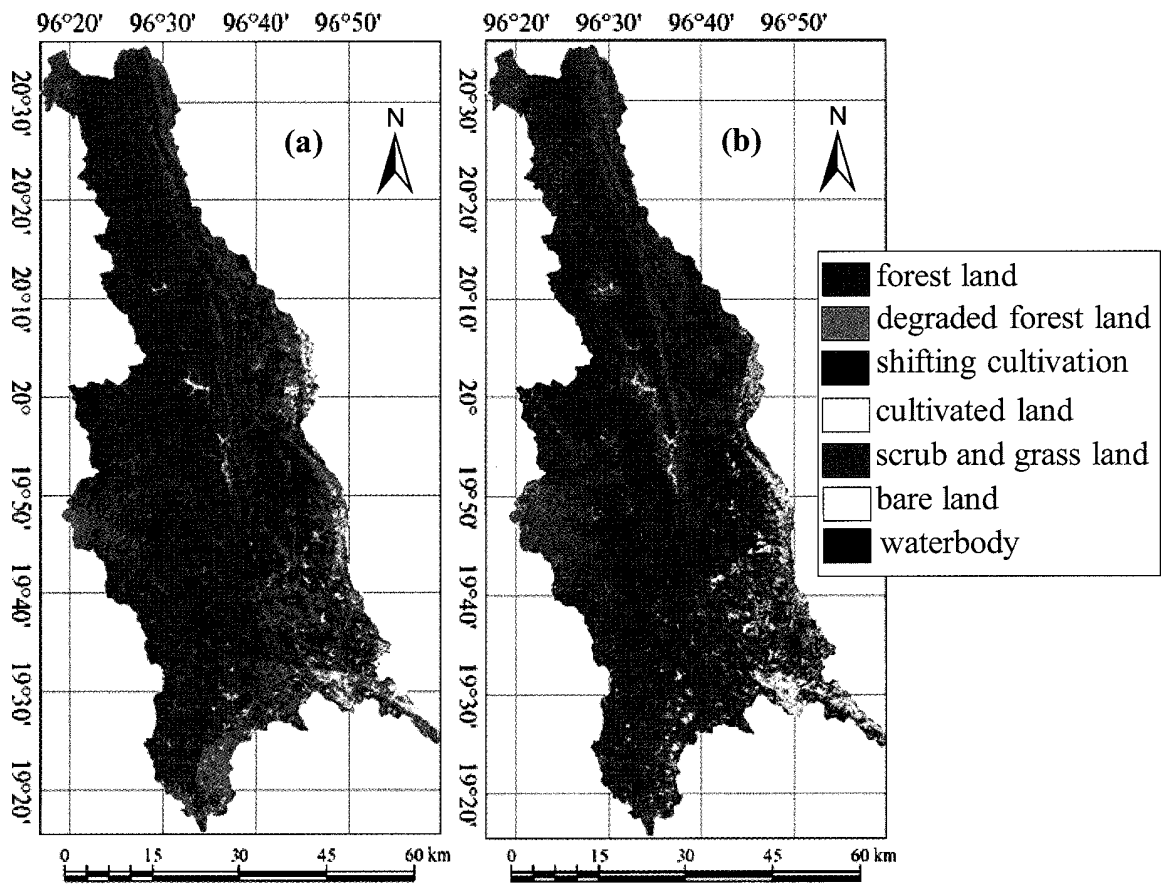

Fig. 3 Land cover classification of Paunglaung watershed, 1989 and 2000 


\section{Logistic Regression Model}

Logistic regression model was constructed based on the spatial attributes of the randomly distributed points, i.e. 666 for deforestation and 2,535 observation points for no-deforestation. All eight predictor variables that were entered into the model passed the multicollinearty test and were fitted in the logistic regression model. Logistic regression model revealed that elevation, soil types, forest area under logging activities, distance to roads, distance to towns and distance to water resources were the significant factors in predicting the possibility of deforestation (Table 6).

Out of the six independent variables which are significant in the model, two variables; areas under logging activities and distance to roads are positively related with deforestation at the significant levels of 0.000 and 0.008 respectively. In the case of distance to roads, that factor is positively related with deforestation and it means that areas which are located far from main road have high possibility for deforestation. In this analysis, we could use only the effect of main roads. There might be significant effect of logging roads in the study area. Therefore, the effect of distance to roads to predict deforestation might be undetected. On the other hand, area under logging activities was also the significant factor in the logistic regression model.

The other predictor variables; i.e. elevation, soil types, distance to towns and distance to water resources were negatively related with deforestation at the significant levels of $0.011,0.037,0.000$ and 0.000 respectively. According to the results of logistic regression, if the elevation becomes higher, the probability of deforestation becomes lower. The possibility of deforestation of the areas located far from the towns becomes lower than that of the areas close to the towns. Similarly, the areas closed to water resources have higher possibility of deforestation than the areas far form the water resources.

Factor of soil types is negatively related with deforestation, i.e. we gave high priority for the mountainous brown forest soil and SPSS modeled the relationship with highest numerical variables. Deforestation was mostly observed in the regions of meadow and meadow alluvial soil and red earths and yellow earths. These soil types are good for paddy land and very suitable for cultivation of seasonal and perennial crops (SetTlement and LAND Record Department, 2002).

The importance of contribution of each variable in the model can be estimated by wald statistics. The higher the value of wald statistic in the model, the more important it is (CHAN, 2004). In logistic regression results (Table 6), distance to water resources has the highest contribution to prediction (Wald $=44.594$ ) of deforestation followed by the distance to towns (Wald=22.676) and then area under logging activities (Wald=20.231).

\section{DISCUSSIONS}

During a period of 11 years, $0.7 \%$ of the forest cover was annually lost in Paunglaung watershed. The estimated deforestation rate of study area; $0.7 \%$ was higher than the estimated annual deforestation rate by Forest Department, Myanmar (ForEST DEPARTMENT, 2003; ThAN, 2000) and lower than that of FRA 2000 and 2005 by FAO at the national level. This might be because of using different remote sensing data, different technologies and also performed by different persons.

Forests are being converted into degraded forests due to increased population in the down-stream areas and consequently, encroachment upon the forest lands is gradually increasing (MYINT et al., 2002). Due to gradually increasing population (Local Administrative Offices), total areas of cultivated land and shifting cultivation also increased up to $288 \mathrm{~km}^{2}(6.2 \%)$ and $630 \mathrm{~km}^{2}(14.0 \%)$ respectively in extent at 2000. Some forest areas of eastern parts were converted to agricultural land; i.e. farmlands growing green tea and orange which are the important economic products for household income at that region. The proximate causes of forest loss vary widely among Asian countries, though conversion for agricultural purposes is common. This study is also consistent with the results that one of the driving forces of deforestation

Table 6 Logistic regression result for deforestation

\begin{tabular}{|c|c|c|c|c|c|c|c|c|c|}
\hline & $\mathrm{B}$ & S.E. & Wald & $\mathrm{df}$ & Sig. & $\operatorname{Exp}(\mathrm{B})$ & $x^{2}$ & $\begin{array}{c}\mathrm{P} \\
\text { value }\end{array}$ & $\mathrm{R}^{2}$ \\
\hline slope & -0.066 & 0.078 & 0.726 & 1 & 0.394 & 0.936 & 210.13 & 0.000 & 0.103 \\
\hline elevation & -0.184 & 0.073 & 6.396 & 1 & 0.011 & 0.832 & & & \\
\hline soiltypes & -0.162 & 0.078 & 4.337 & 1 & 0.037 & 0.851 & & & \\
\hline logging/non & 0.570 & 0.127 & 20.231 & 1 & 0.000 & 1.768 & & & \\
\hline dis-road & 0.016 & 0.006 & 6.978 & 1 & 0.008 & 1.016 & & & \\
\hline dis-town & -0.033 & 0.007 & 22.676 & 1 & 0.000 & 0.967 & & & \\
\hline dis-water & -0.098 & 0.015 & 44.594 & 1 & 0.000 & 0.907 & & & \\
\hline dis-village & 0.001 & 0.003 & 0.031 & 1 & 0.860 & 1.001 & & & \\
\hline Constant & 0.727 & 0.300 & 5.864 & 1 & 0.015 & 2.068 & & & \\
\hline
\end{tabular}

notes: logging/non: area under logging or not, dis-road: distance to roads, dis-town: distance to towns, dis-water: distance to water resources, dis-villages: distance to villages. 
is expansion of agricultural land (LeIMGRUBER et al., 2006; SONGER, 2006).

Shifting cultivation by indigenous ethnic groups is still considered a major cause of forest loss in the mountain zones of Myanmar, where there is an increasing pressure for land by the growing population (STIBIG et al., 2007). Shifting cultivation is a common farming system traditionally practiced since time immemorial in the study area (ZIN et al., 2002; MYINT et al., 2002). The fallow period of shifting cultivation is reduced today because of increased population and limited land availability (ZIN et al., 2002). On the other hands, the forests are also fragmented due to shifting cultivation and become open. Gap planting should be introduced in open areas to increase the forest cover. Community forestry and agroforestry could be viable options to reverse the current trend of deforestation (ZIN et al., 2002).

According to the logistic regression results, forest areas located near the human settlement have high possibility to cause deforestation. The perspective of future research should be conducted to predict the drivers of deforestation based on increased population rate of the local communities, the detail information of their livelihood and how much that community depends on surrounding forests.

In Myanmar, shifting cultivation, logging and forest fire play a dominant role in forest degradation and forest type conversion (GIRI et al., 2003). In this logistic regression model, areas under logging activities were significant and also one of the affecting factors of deforestation in the study area. The results of land cover change assessment and logistic regression show that deforestation took place especially in the low elevation area. Forest cover changes were observed mostly in the areas where soil types are good for agricultural purpose. That results were supported by the hypothesis of other research; biophysical and locational factors are strong determinants of regional deforestation, specifically, lower elevation and well-drained upland soils are more likely to cause deforestations (GEOGHEGAN et al., 2004; MAS et al., 2004; CHOWDHURY, 2006).

The possibility of deforestation is low in the high elevation area. As the saying goes "Prevention is better than cure", it would be prudent to constantly monitor the factors which contribute to deforestation. An effective watershed management programme should be launched according to an example of a multi-disciplinary way by local people participation and awareness conducted by Forest Department under the project of MYA/93/005 (THAN et al., 1990; GAF, 1996).

\section{CONCLUSIONS}

Forest cover decreased during a period of 11 years and $0.7 \%$ of the forest cover was annually lost in Paunglaung watershed. Continued degradation of the forest resources will ultimately result in deforestation. Sustainability of Paunglaung watershed is necessary for social, eological and economic benefits. However, deforestation can be prevented through the application of effective management. With this respect, this study demonstrates and suggests a spatial logistic regression model to predict the possibility of driving factors for deforestation. Based on these results, effective remedial measures can be conducted to prevent deforestation in the study area. The quality of the current analysis for predicting deforestation could be improved by using together with socioeconomic variables of local communities and other environment factors. Spatial information obtained by integrated application of RS and GIS is particularly an important basis for decision making process in natural resource management. The authors convince that the predicted driving factors of deforestation in this study will provide useful information for effective management of natural resources in Myanmar.

\section{LITERATURE CITED}

BaWA, K. S. and DaYanandan, S., (1997): Socioeconomic factors and tropical deforestation. Nature 386 (6625): 562-563

Belsley, D. A., KuH, E. and Welsch, R. E., (1980): Regression diagnostics: Identifying influential data and sources of collinearity. New York. John Wiley \& Sons

CHAN, Y. H., (2004): Biostatistics 202. Logistic regression analysis. Singapore Med. J. 45(4): 149-153

CHOWDHURY, R. R., (2006): Driving forces of tropical deforestation: The role of remote sensing and spatial models, Singapore Journal of Tropical Geography 27(1): 82-101

ESCAP., (1997): Guidelines and manual on land-use planning and practices in watershed management and disaster reduction. Economic and Social Commission for Asia and the Pacific (ESCAP), United Nations

FAO., (2005): Forest resources assessment 2005. Food and Agriculture Organization of United Nations, Rome

FEARnside, P. M., (1997): The main resources of Amazonia. Latin American Studies Association (LASA) XX International congress. Guadalajara, Mexico

Forest Department, (1998a): Project planning for forest area and watershed conservation in Paunglaung watershed area. Forest Department, Yamethin District, Mandalay Division, Myanmar

Forest DEPARTMENT, (1998b): Project planning for forest area and watershed conservation in Paunglaung watershed area. Forest Department, Kalaw District, Shan State, Myanmar

Forest Department, (2003): Forestry in Myanmar. Ministry of Forestry, Yangon, Myanmar

GAF, (1996): Mapping and land use planning for watershed management, Watershed management for three critical areas. Consultant report, Volume I: MYA/93/005, UNDP and FAO: MYA/93/026

GaRSON, G. D., (1998): Neural networks: An introductory guide for social scientists. London, Sage Publications

Gautam, A. P., Webb, E. L., Shivakoti, G. P. and Zoebisch, M.A., (2003): Land use dynamics and landscape change pattern in a mountain watershed in Nepal. Agriculture, Ecosystems and Environment 99(1-3): 83-96

Geoghegan, J., Schneider, L. C. and Vance, C., (2004): Spatially 
explicit, statistical land-change models in data-poor conditions. In integrated land-change science and tropical deforestation in the Southern Yucatán: final frontiers. B. L. Turner II, J. Geoghegan, and D. Foster (eds). Oxford Geographical and Environmental Studies, Clarendon Press of Oxford University Press

Giri, C., Defourny, P. and Shrestha, S., (2003): Land cover characterization and mapping of continental Southeast Asia using multi-resolution satellite sensor data. International Journal of Remote Sensing 24(21): 4181-4196

GuPTA, S., Porwal, M. C. and Roy, P.S., (2004): Human modification of the tropical rain forest of Nicobar Islands: Indicators from land use land cover mapping. Journal of Human Ecology 16 (3): 163-171

HOWARTH, P.J. and WICKWARE, G. M., (1981): Procedures for change detection using Landsat digital data. International Journal of Remote Sensing 2(3): 277-291

Hutchinson, C. F., (1982): Techniques for combining Landsat and ancillary data for digital classification improvement. Photogrammetric Engineering and Remote Sensing 48(1): 123-130

IrRigation Department, (2004): Paunglaung multi-purpose dam project report. Irrigation Department, Ministry of Agriculture and Irrigation, Myanmar

LAmbin, E. F., (1994): Modelling deforestation processes, A review, TREES series B: Research Report, Joint Research Center, Institute for Remote Sensing Applications; European Space Agency, Luxembourg, Office for Official Publications of the European Community

Leimgruber, P., Kelly, D. S., Steininger, M. K., Brunner, J., Mueller, T. and Songer, M. A., (2006): Forest cover change patterns in Myanmar (Burma) 1990-2000. Environmental Conservation 32: 356-364

Mas, J. F., Puig, H., Palacio, J. L. and Sosa-Lopez, A., (2004): Modelling deforestation using GIS and Artificial Neutral networks. Environmental Modelling and Software 19(5): 461-471

Mas J. F., Sosa-Perez, A., Palacio, J. L. and Puig, H., (2000): Modelling Deforestation in the region of the Lagoon of Terminos, South East Mexico. Proceedings of the ASPRS (American Society of Photogrammetry and Remote Sensing) annual convention, Washington

MenARD, S., (1995): Applied logistic regression analysis. Quantitative Applications in the Social Sciences, Sage University Paper Series, 106. Thousand Oaks, CA: Sage Publications

Mertens, B. and Lambin, E. F., (1997): Spatial modelling of deforestation in Southern Cameroon: Spatial disaggregation of diverse deforestation processes. Applied Geography 17(2): 143-162

Myint, W.W., Mon, M.S. and Kyı, K.M., (2002): Sustainability of natural resources through NWFP based income Generation activities in Paunglaung watershed area. Proceeding of Annual Research Conference 2002, Myanmar Academy of Agricultural, Forestry, Livestock and Fishery Sciences, Yangon, Myanmar, 152174

Nagendra, H., Southworth, J. and Tucker, C., (2003): Accessibility as a determinant of landscape transformation in Western Honduras: linking pattern and process. Landscape Ecology 18(2): 141-158

PAMpel, F.C., (2000): Logistic regression: a primer, Quantitative Applications in the Social Sciences, Sage University Paper Series 07-132, Thousand Oaks, CA: Sage Publication.
SchWAB, A. J., (2004): Logistic regression, complete problems, Data analysis and computers II. School of Social Work, University of Texas at Austin

Serneels, S. and Lambin, E. F., (2001): Proximate causes of land-use change in Narok District, Kenya: A spatial statistical model. Agriculture, Ecosystems and Environment 85(1-3): 65-81

Settlement and Land Record Department., (2002): Gateway to Land and Water Information: Myanmar national report FAO. Ministry of Agriculture and Irrigation, Yangon, Myanmar

SIDJAK, R. W. and WHEATE, R.D., (1999): Glacier mapping of the Illecillewaet ice field, British Columbia, Canada, using Landsat TM and digital elevation data. International Journal of Remote Sensing 20(2): 273-284

SONGER, M. A., (2006): Endangered dry deciduous forests of upper Myanmar (Burma): A multi-scale approach for research and conservation, $\mathrm{PhD}$ thesis, University of Maryland, College Park, MD 20742, USA

Southworth, J., Munroe, D. and Nagendra, H., (2004): Land cover change and landscape fragmentation-comparing the utility of continuous and discrete analyses for a western Honduras region. Agriculture, Ecosystems and Environment 101(2-3): 185-205

Stibig, H. J., Stolle, F., Dennis, R. and Feldkötter, C., (2007): Forest cover change in Southeast Asia, The regional pattern, JRC Scientific and Technical Report, JRC 38221, EUR 22896 EN, ISSN 1018-5593, Italy

Tekle, K. and Heduund, L., (2000): Land cover changes between 1958 and 1986 in Kalu District, Southern Wello, Ethiopia. Mountain Research and Development 20(1): 42-51

Than, K. M., Lwin, T., Thet, S. and Lwin, S., (1990): Watershed management in Myanmar. Forest Department, Yangon, Myanmar

Than, M. M., (2000): Review of land use and land degradation status in Myanmar, desertification, land degradation, deforestation, drought and their environmental and socioeconomic impacts. Proceedings of the National Workshop on Preparation of the UNCCD National Action Programme, Yangon, Myanmar

Tucker, C. M., Munroe, D. K., Nagendra, H. and Southworth, J., (2005): Comparative Spatial Analyses of Forest Conservation and Change in Honduras and Guatemala. Conservation and Society 3(1): $174-200$

Wildujfe Conservation SocieTy., (1997): Tiger survey report of Paunglaung catchment. Wildlife Conservation Society, Yangon, Myanmar

Zhao, S., Peng, C., Jiang, H., Tian, D., Lei, X. and Zhou, X., (2006): Land use change in Asia and the ecological consequences, The Ecological Society of Japan. Ecological Research 21 (6): 890-896

ZIN, M. T., (2005): Developing a scientific basis for sustainable management of tropical forest watersheds, $\mathrm{PhD}$ thesis, Universitatsverlag Göttingen

Zin, M. T., HTun, N. Z, AyE, M. M., Win, K. N. and Sein, C. C., (2002): Assessing extension needs for community forestry development in Paunglaung watershed. Proceeding of Annual Research Conference 2002, Myanmar Academy of Agricultural, Forestry, Livestock and Fishery Sciences, Yangon, Myanmar, 175-196

(Received 31 July 2008) (Accepted 17 November 2008) 